\title{
A ruptura de um Projeto Político Pedagógico Na periferia das periferias
}

\author{
Maria Cristina Schefer ${ }^{*}$ \\ GELSA KNIJNIK
}

\begin{abstract}
RESUMO: O projeto político pedagógico (PPP) é um dos documentos representativos da gestão Democrática na escola. Nele constam as proposições das comunidades escolares que podem dar singularidade ao processo educativo. Este estudo, de tipo etnográfico, que teve como base a legislação nacional e as contribuições de Bauman, evidencia o impedimento da gestão de um PPP, em vista de um "ato administrativo de costume": o banimento de profissionais da educação de escolas centrais para uma escola da periferia das periferias.
\end{abstract}

Palavras-chave: Gestão democrática. Depreciação profissional. Atos administrativos

\section{The rupture of a political pedagogical project (PPP)}

On the periphery of the peripheries

\begin{abstract}
The political pedagogical project (PPP) is one of the representative documents for democratic management in the school. It contains the proposals of the school communities which can give unity to the educational process. This ethnographic study, based on the national legislation and the contributions of Bauman, shows the impediments to the management of a PPP, in view of a "normal administrative act": the banishment of professionals from education in central schools to schools on the periphery of the peripheries.
\end{abstract}

* Doutora em Educação pelo Programa de Pós-Graduação da Universidade do Vale do Rio dos Sinos - UNISINOS. Atualmente, atua como Pedagoga no Instituto Federal de Educação (IFRS), Ciência e Tecnologia do Rio Grande do Sul - campus/Osório, e é membro do Grupo Interinstitucional de Pesquisa em Educação Matemática e Sociedade (GIPEMS) da Unisinos. Capão da Canoa/RS-Brasil. E-mail: <mariacrisdomar@gmail.com>.

** É Doutora em Educação e Mestre em Matemática pela Universidade Federal do Rio Grande do Sul. É professora titular do Programa de Pós-Graduação em Educação da Universidade do Vale do Rio dos Sinos (Unisinos). São Leopoldo/RS - Brasil. E-mail: <gelsa.knijnik@gmail.com>. 
Keywords: Democratic management. Professional depreciation. Administrative acts.

\section{La ruptura de un proyecto político pedagógico (PPP)}

En la periferia de las periferias

RESUMEN: El proyecto político pedagógico (PPP) es uno de los documentos representativos de la administración Democrática en la escuela. En él se encuentran las proposiciones de las comunidades escolares que pueden otorgar singularidad al proceso educativo. Este estudio, del tipo etnográfico, ha tenido como base la legislación nacional y las contribuciones de Bauman y revela el impedimento de la gestión de un PPP provocado por un "acto administrativo co-

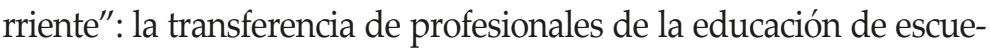
las centrales a una escuela de la periferia de las periferias.

Palabras clave: Gestión democrática. Depreciación profesional. Actos administrativos.

\section{La rupture d'un projet politique pédagogique (PPP)}

Dans la périphérie des périphéries

Résumé: Le projet politique pédagogique (PPP) est un des documents représentatifs de la gestion démocratique de l'école. Il contient les propositions des communautés scolaires qui peuvent donner de la singularité au processus éducatif. Cette étude, de type ethnographique, qui se base sur la législation nationale et sur les contributions de Bauman, montre la destitution de la gestion d'un PPP, en vue d'un "acte administratif de coutume ": le banniment de professionnels de l'éducation d'écoles centrales pour une école de la périphérie des périphéries.

Mots-clés: Gestion démocratique. Depréciation professionnelle. Actes administratifs.

\section{Introdução}


A Lei de Diretrizes e Bases da Educação Nacional, vigente desde o ano de 1996, que normatiza a gestão democrática das escolas, determina tanto a necessidade da construção de propostas pedagógicas quanto da participação docente. Esse encaminhamento é importante, pois o desmembramento dos objetivos previstos nas propostas pedagógicas depende, em grande parte, das ações dos docentes em sala de aula. Pela inerente conotação política, as propostas podem ser denominadas de projetos políticos pedagógicos (PPPs), seguindo uma orientação teórica progressista.

A desconsideração das características dos educandos aumenta a probabilidade de insucesso escolar, portanto, os profissionais que uma escola recebe "estão dotados" de expectativas administrativas para a efetivação do processo educativo. Em lugares de extrema pobreza, em que as famílias têm pouca aproximação com a cultura escolar, o correto, se pensarmos em 'equidade de oportunidades sociais', seria o aumento de investimentos públicos, incluindo a formação específica dos profissionais para a atuação em meio às adversidades.

Ao contrário disso, este estudo descritivo, apresenta uma prática "de costume", de acordo com o campo do Direito, que é a designação de profissionais destituídos retoricamente de atributos qualificatórios, num determinado período de governo, para as escolas frequentadas pelas populações mais pobres. Revela, portanto, o descumprimento dos princípios da administração pública brasileira (Limpe) e promove, entre outros danos, a fragilização do PPP.

Enfim, com viés etnográfico, descrevo aqui o indizível, profissionais da educação "de castigo" numa escola de periferia. Um PPP enfraquecido por uma reunião excludente, que institui um processo educativo a menor para os que mais necessitam. Os dados foram coletados entre 2010 e 2014, período em que realizei o doutoramento em educação. Para registrá-los foi utilizado um Diário de Campo, onde constam relatórios de episódios-chave, entrevistas audiogravadas e transcritas e imagens fotográficas.

\section{A metodologia com viés etnográfico}

Com origem nos estudos antropológicos, conforme Guber (2001), as pesquisas do "tipo etnográfico" (ANDRÉ, 1976) ou a "etnografia em educação" (GREEN et al., 2005) passaram a ser utilizadas no campo educacional com vistas à compreensão de culturas escolares, rompendo com a tradição cognitivista que perdurou na pesquisa educacional brasileira até meados da década de 70 .

Por ser um sistema aberto de investigação, conforme Green (2005), as pesquisas com viés etnográfico não permitem categorizações de "achados" em campo, não suportam o 'é isso ou aquilo'. Resultam de registros interpretativos ou “descrições densas" (GEERTZ, 1989), que "traduzem" (a partir do ponto de vista do investigado) o sentido das práticas 
de lugar. Ao investigador cabe o papel primeiro de escrevente da história alheia. Para Green (2005), quem deseja fazer estudos dessa natureza não pode definir a priori o que será ou não tomado para análise, visto o caráter desenvolvimental da metodologia.

Entrevistas abertas, narrativas, seleção de episódios-chave, fotografias, documentos e aportes teóricos podem compor o Diário de Campo do investigador que, para Minayo (2012, p. 71), "nada mais é do que um caderninho, uma caderneta, ou um arquivo eletrônico no qual escrevemos todas as coisas que não fazem parte do material formal de entrevistas em suas várias modalidades". Os instrumentos foram utilizados neste estudo, quando fiquei por quatro meses ininterruptos em campo. Na ocasião, eu havia sido nomeada para a função de apoio pedagógico na escola em estudo e havia iniciado o doutorado. Findado esse período contínuo, ainda retornei ao lugar durante os dois anos que se seguiram ao campo, às vezes em momentos festivos e outras vezes em reuniões pedagógicas. Porém, foi a proximidade inicial com os profissionais da escola que garantiu o desenvolvimento do estudo; conforme Weber (2009), a pesquisa etnográfica resulta da empatia entre os participantes do processo investigativo.

O investigador sempre chega a campo com uma bagagem conceitual/referencial. No meu caso, como decidi compreender a dinâmica da gestão escolar, das relações entre os gestores e os profissionais da escola, utilizei como base tanto a legislação quanto reflexões de intelectuais que contribuem discursivamente para legitimar o normatizado ou para explicar suas fragilidades. Apresento a seguir parte da legislação que norteou meu estudo, metodologicamente, nomeado como do "tipo etnográfico" (ANDRÉ, 1979), mas que seguiu as orientações de Green et. al. (2005), no tratamento e análises das informações.

\section{Constituição, atos administrativos e a Lei}

A Constituição de 1988, conhecida como a "Constituição Cidadã", é o documento de referência para as ações públicas no Brasil. Ela institui o Estado Democrático de Direito. Entre os princípios fundamentais, vale destacar para este estudo: "II - a cidadania; III - a dignidade da pessoa humana; V - o pluralismo político", bem como os seguintes objetivos,

I - construir uma sociedade livre, justa e solidária; [...]; III - erradicar a pobreza e a marginalização e reduzir as desigualdades sociais e regionais; IV - promover o bem de todos, sem preconceitos de origem, raça, sexo, cor, idade e quaisquer outras formas de discriminação.

Esses excertos dizem respeito à vida das pessoas, as quais se encontram nas escolas, sejam professores, técnicos, pais, alunos. Nessa linha, também o inciso III do art. 19 
torna-se fundamental: "é vedado à União, aos Estados, ao Distrito Federal e aos Municípios: [...] III - criar distinções entre brasileiros ou preferências entre si".

No que se refere às relações com os profissionais das escolas, é possível questionar as decisões administrativo-pedagógicas dos governantes (agentes políticos) a partir do disposto no art. 37:

A administração pública direta e indireta de qualquer dos Poderes da União, dos Estados, do Distrito Federal e dos Municípios obedecerá aos princípios de legalidade, impessoalidade, moralidade, publicidade e eficiência e, também, ao seguinte: [ ] II - a investidura em cargo ou emprego público depende de aprovação prévia em concurso público de provas ou de provas e títulos, de acordo com a natureza e a complexidade do cargo ou emprego, na forma prevista em lei, ressalvadas as nomeações para cargo em comissão declarado em lei de livre nomeação e exoneração. [ ] $\S 2^{\circ}-$ A não observância do disposto nos incisos II e III implicará a nulidade do ato e a punição da autoridade responsável, nos termos da lei.

Em constante aperfeiçoamento ${ }^{1}$, a Constituição disciplina os "atos administrativos" do poder público. Quando agentes políticos (que durante mandatos governam) agem a partir dela, eles operam para o bem comum. Porém, como descreverei nestas linhas, nem sempre isso acontece. Muitas vezes, os princípios da impessoalidade, da eficiência, e da legalidade que a regem são ignorados por atos gestores marcados por interesses partidários, financeiros, afins.

\section{Compreendendo o ato administrativo}

Para compreender melhor um ato administrativo, coube-me a ajuda específica do campo do Direito. O intuito, neste estudo, foi escrutinar processos de nomeação e reaproveitamento de profissionais da educação que resultam na designação do lugar para a entrada em exercício sob pena de perda de cargo público. Na lição de Meirelles et al.,

ato administrativo é toda manifestação unilateral de vontade da administração pública que, agindo nessa qualidade, tenha por fim imediato adquirir, resguardar, transferir, modificar, extinguir e declarar direitos, ou impor obrigações aos administrados ou a si própria. (2011, p. 154).

Para o jurista (2011), a validade de um ato tem cinco características principais, a saber, a competência, o motivo, o objeto, a finalidade e a forma. A competência tem a ver com a pessoa legalmente apta (competente) para praticar um ato administrativo. No caso da nomeação para professor, caberá isso ao prefeito ou a quem ele legalmente determinar. Já a "disponibilidade e o reaproveitamento" de profissionais para uma escola, geralmente, é da alçada dos gestores da pasta educacional e de suas equipes diretivas. O motivo tem a ver com a causa do ato administrativo, como, por exemplo: necessidade 
de "aproveitamento", de nomeação. O objeto do ato administrativo, segundo Meirelles et al. (2011, p. 159), "identifica-se com o conteúdo do ato, através do qual a Administração manifesta seu poder e sua vontade, ou atesta simplesmente situações preexistentes". A finalidade do ato administrativo, para Meirelles et al. (2011) é sempre o bem comum, a coisa pública. A forma do ato administrativo é o meio padronizado para que a vontade dos agentes públicos (interna ou externamente) seja exteriorizada, no entender de Meirelles et al. (2011).

Não é preciso ser um profissional do Direito para perceber que o elemento do ato administrativo que pode servir para aproveitamentos/nomeações excludentes de profissionais da educação é a finalidade, visto que tende à subjetividade, possibilitando desvios, os quais podem ser encobertos por uma forma perfeita na publicação de um ato. Ou seja, o atendimento ao "design burocrático" pode descaracterizar, aos olhos da maioria, a natureza abusiva de um ato administrativo, o desvio de finalidade.

\section{Gestão democrática e propostas pedagógicas}

A Lei de Diretrizes e Bases da Educação Nacional (Lei 9394/96), que disciplina a educação escolar no território nacional, traz no art. $3^{0}$ os princípios norteadores, sendo que dois interessam de forma singular a este estudo: "VII - valorização do profissional da educação escolar; VIII - gestão democrática do ensino público, na forma desta Lei e da legislação dos sistemas de ensino". (MEC, 1996). Ambos interferem diretamente nas práticas cotidianas da escola, e é a partir da gestão democrática que pode ser garantida a construção de uma proposta pedagógica (ou de um projeto político pedagógico [PPP]) significativa, no qual a valorização dos profissionais da educação é o meio de engajamento para a execução. Referente a isso a LDB determina em seu art. 12 que

\footnotetext{
Os estabelecimentos de ensino, respeitadas as normas comuns e as do seu sistema de ensino, terão a incumbência de: I - elaborar e executar sua proposta pedagógica; [...]", e o art. 13 estabelece: “Os docentes incumbir-se-ão de: I- participar da elaboração da proposta pedagógica do estabelecimento de ensino; II - elaborar e cumprir plano de trabalho, segundo a proposta pedagógica do estabelecimento de ensino; [...]." (MEC, 1996).
}

Porém, mesmo que às competências docentes tenham sido referenciadas como importantes aos processos decisórios da escola, como impresso na LDB, na prática essa participação/valorização nem sempre ocorre. A exemplo do que ocorre no lugar que, então, apresento.

\section{O lugar escolar, os profissionais e a redondeza}


Uma escola que quase desabou, em 2010, dois meses depois da inauguração (prédio de alvenaria que deveria substituir o antigo de madeira), situada na região metropolitana de Porto Alegre, foi o lugar de estudo. A instituição conta com mais de duzentos alunos, distribuídos entre a educação infantil e os anos iniciais do ensino fundamental. As atividades educativas tiveram início há 22 anos, com o objetivo de "acolher" os dependentes dos, então, trabalhadores da construção civil, que se instalaram na região no período de construção do Polo Petroquímico de Triunfo, mão de obra sem formação, que, após o término das obras, foi "dispensada".

Acomodados numa das áreas mais distantes do centro da cidade, naquilo que a partir de uma análise se degrada do obelisco para as margens, nomeei como sendo a "periferia das periferias". Uma posição territorial que (de saída) prescreveu a miséria aos forasteiros, bem como seu distanciamento dos moradores com melhor condição de vida.

Diante dessa condição de pobre (herdada) e sem capacitação profissional, os moradores do lugar estão há duas décadas sujeitos a postos de trabalho sazonais nas indústrias da região, ou em ocupações informais, de pouca remuneração.

Essa falta de contratantes formais pode ser explicada por Bauman (2008, p. 15), nos seguintes termos: "As pessoas em busca de trabalho precisam ser adequadamente nutridas e saudáveis, acostumadas a um comportamento disciplinado e possuidoras das habilidades exigidas pelas rotinas de trabalho dos empregos que procuram." A continuidade da miséria (que não permite uma boa saúde/aparência aos habitantes) contribui para a manutenção da mão de obra barata e da informalidade no lugar. Segundo Santos (2008), todos os lugares são sublugares de um sistema, refletem as normas de um modo de produção, existem e se mantêm de um jeito e não de outro no atendimento às regras econômicas. Em síntese, "quando se fala em modo de produção, não se trata simplesmente de relações sociais que tomam uma forma material, mas também de seus aspectos imateriais, como o dado político e ideológico". (SANTOS, 2008, p. 32).

Uma região marcada pela pobreza (pelas faltas) nada tem a ver com a "falta de vontade" ou a "vagabundice" dos habitantes (conforme o senso comum tende a difundir/ culpabilizar) e dificilmente poderá ser modificada sem que haja uma interferência específica para a melhoria do lugar.

Quanto às dezessete professoras e os demais profissionais da educação, destinados a ensinar num lugar marcado pelo descaso, pela falta de direitos, nove contam "em detalhes" que estão na escola "de castigo": ou porque "subverteram" a equipe administrativa ou porque não foram considerados dignos de outra designação (caso das recém-nomeados). Muitos revelaram que já chegaram "loucos para partir", conforme o depoimento das professoras,

Eu vim porque quis [...], mas a gente rê que muita gente não vem pra cá porque quer, vem como um castigo, e tem vários outros que moram perto, fica mais à mão. Não é por uma opção, porque eu acho que aquele lugar é legal, são poucos os que vieram pra cá assim. (Transcrição de parte da entrevista sonora com A, em set. 2012). 
Normalmente [quem vem para cá] são aquelas que a secretária não as quer nas outras escolas. Existem muitas razões pelas quais elas vêm, às vezes por serem pessoas que batem de frente com outras escolas, com a equipe diretiva e outros grupos ou por "castigo", pra ti aprender porque tu não forma o círculo deles, tu é um pouco diferente, então, normalmente, é por castigo. Eu sou uma. Bati de frente com eles. (Transcrição de parte da entrevista sonora com B, em set. 2012).

O organograma escolar apresenta uma força de trabalho 100\% feminina, o que inclui a única professora transexual do município e um auxiliar de nutrição gay, o que merece um olhar na perspectiva de gênero, pois é no mínimo curioso que não tenham docentes "homens" com características "transgressoras" similares a serem postos em disponibilidade nas escolas centrais... Nesse cenário, Almeida dá conta de que

o processo de imputar para homens e mulheres determinismos sexuais biologicamente herdados implica a existência de uma ditadura de gênero para os dois sexos que, infalivelmente, leva a hierarquia do masculino sobre o feminino, numa escala axiológica na qual as fêmeas sempre saem perdendo, dado que as atividades masculinas sempre foram consideradas de primeira ordem e as femininas, de segundo escalão. Essa dupla (des)valorização conduz a diferentes implicações no mundo do trabalho, no espaço público, nas esferas do privado e nas instâncias do poder. (1998, p. 44).

Outros atributos das profissionais da escola causam similar estranheza: duas das assistentes da educação infantil são deficientes físicas: uma é cadeirante, e a outra sofreu paralisia infantil. Ambas têm dificuldades de locomoção para acompanhar o "tranco" dos pequenos com quem atuam. Uma professora tem obesidade mórbida (EI) e partilha com a diretora a permanente possibilidade de sofrer um ataque epilético. Três professoras enfrentam depressão crônica pós-abstinência química por uso de drogas. Na cozinha da escola, dois dos profissionais desenvolvem doenças degenerativas (soro positivos) e contam com o auxílio diário de duas mães voluntárias que trabalham em troca das sobras da merenda.

Esse agrupamento de profissionais evidenciou que as designações para a entrada em exercício na escola da periferia das periferias, obedece a critérios mercadológicos, que servem como réguas excludentes: as questões de gênero, a deficiência física, as doenças psicossomáticas ou degenerativas, a insignificância partidária e a falta de afinidade com a gestão. Em outros termos, o que opera é a lógica capitalista de uma 'Sociedade de Consumo Líquido-Moderna' (BAUMAN, 2008), em que há um processo de depreciação de tudo e de todos que não interessam àqueles que ditam as regras sociais. Para Bauman (2009, p. 108), “a política de vida [...], assim como a natureza das relações interpessoais, tende a ser remodelada à semelhança dos meios e objetos de consumo e segundo as linhas sugeridas pela síndrome consumista"1. Pensando em termos ideológicos, são as correntes neoliberais, operando em defesa do capital, inibindo as ideias democratizantes do ensino, conforme Leher (2002, p.197), ções ideológicas assentadas em valores, normas, atitudes, aptidões, que, apesar 
de aparentemente corresponderem ao interesse de todos, interessa mais particularmente ao grupo dirigente.

Quanto à manutenção de "profissionais em acordo com os gestores" nas escolas centrais, ela pode ser explicada tanto pelo poder de persuasão que os mais ricos sempre detiveram para garantir o ensino de qualidade "aos seus" quanto pelas expectativas de retorno social que "os filhos do centro" carregam. Conforme Clark apud Bauman,

toda a ideia de escolas e universidades é para aumentar a taxa de crescimento econômico e ajudar-nos a competir com nossos "parceiros europeus", e assim também (poderíamos acrescentar) ajudar o governo a vencer a próxima eleição. (2009, p. 40).

A prática "de costume"3 (mesmo que inapropriada a atos administrativos) a que recorrem certos gestores públicos quando passam a "dar menos aos que têm menos" mostra o quanto as escolas estão subordinadas aos ditames comerciais, bem como o quanto a gestão democrática pode ter sido reduzida à elaboração obrigatória dos PPP.

\section{O PPP e a implicação prática dos atos administrativos}

Ícone da gestão democrática, da socialização de saberes, da possibilidade de se fazer justiça social por meio do ensino, o PPP permite à equipe de profissionais e à comunidade buscar alternativas conjuntas (a partir da realidade) para garantir o aprendizado na escola.

Entretanto, segundo Veiga,

a gestão democrática implica principalmente o repensar da estrutura do poder da escola, tendo em vista sua socialização. A socialização do poder propicia a prática da participação coletiva que atenua o individualismo; da reciprocidade, que elimina a exploração; da solidariedade, que supera a opressão da autonomia, que anula a dependência de órgãos intermediários que elaboram políticas educacionais das quais a escola é mera executora. $(2002$, p. 3).

Quando os profissionais do ensino chegam à escola a partir de um processo que envolve a depreciação de si, de sua atuação profissional, veem-se diante de um dilema: ignorar a própria exclusão e incluir o outro. Para Bauman (2013), permanecer humano em condições desumanas é quase impossível.

A escola em estudo tem um PPP muito bem-guardado na sala da direção, elaborado, de acordo com a diretora, solitária e solidariamente, a partir, "de um recorta e cola entre as escolas, pois mandaram a gente fazer e daí acabei eu tendo que assumir a bronca, pedi ajuda de uma diretora de outra". (Relato /Diário de Campo, jun. 2010). Além disso, a escola nunca teve profissionais de apoio pedagógico, nem ao menos uma 
formação com o objetivo de refletir sobre a construção do documento, "apenas mandaram fazer" (Idem).

Obviamente, a direção tomou uma medida administrativa e cumpriu com a "tarefa" de encaminhar o PPP para aprovação. Diante das contingências que reuniram os profissionais na escola, dificilmente haveria clima para a elaboração conjunta de uma proposta educacional. Conforme Vasconcelos (2004, p. 176), “o projeto deve ser iniciado quando houver por parte da instituição o desejo, a vontade política, de aumentar o nível de participação da comunidade educativa, o real compromisso com uma educação democrática".

Não há como abordar (por falta de espaço), neste texto, o modo como ocorrem as práticas pedagógicas no lugar, porém, ressalto a solidão como característica do trabalho docente e a dificuldade de engajamento para melhorias no processo educativo. São ideias pedagógicas tradicionais: cópias, memorizações, sanções, castigos que me pareceram consensuais, bem como um possível modo de resistência ao sistema (aos gestores), que se dá através de faltas e atrasos dos profissionais (rotineiramente).

Resulta desse todo: evasões, infrequência e baixo índice de aprovação. Em 2012, a escola ficou com a pior nota na "Prova Brasil" no município e na região. Algo previsto, segundo os profissionais,

"Achamos até que se saíram bem, pois a maioria deles nem sabe ler." (Comentário de uma das professoras/Diário de Campo, out. 2012).

"Estávamos esperando esse resultado, não há o que fazer [...], a Secretaria de Educação sabe a situação aqui." (Relato de um membro da Diretoria/Diário de Campo, out. 2012).

A conformidade da equipe de ensino com o resultado dessa avaliação de larga escala coloca as crianças na posição de "vítimas colaterais, sujeitas a baixas colaterais, afetadas por danos colaterais" da gestão democrática do ensino brasileiro, como escreveu Bauman (2008). Para Cohen apud Bauman (2008), esses termos "pertencem ao arsenal linguístico dos 'estados da negação': negação de responsabilidade moral, assim como jurídica". Em suma, são termos que servem para invocar a imprevisibilidade da gestão democrática "sob o argumento da falta de intencionalidade, tem o objetivo de negar ou isentar a cegueira ética, condicionada ou deliberada". (p. 150).

A nota das crianças da escola não atingiu o mínimo determinado pela "Prova Brasil" para ser considerada na tabulação dos resultados. Foi tratada no "mapa educacional" como acidente, desvio. Em outras palavras, indigna de inclusão! 


\section{Considerações finais}

A legislação nacional, tendo por base a Constituição de 1988, disciplina os atos administrativos e a educação escolar. O que deve prevalecer no âmbito do setor público são os critérios de competência e não as afinidades político-partidárias. O projeto político pedagógico, enquanto planificação da gestão democrática num lugar de ensino, somente se concretiza quando há identificação dele com os profissionais de uma escola. Porém, como mostrei neste estudo, são as éticas plurais de uma sociedade de consumo líquido-moderna, que transforma tudo e todos em mercadorias, que têm definido quais os profissionais da educação atuam nos centros das cidades, nas escolas dos homens de bem e quais devem ser enviados para as periferias, para o atendimento dos pobres, dos consumidores falhos.

Se por um lado temos positivados na legislação nacional uma série de direitos comuns a todos, por outro, ações de caráter desenvolvimentista podem estar depreciando professores, técnicos e estudantes e atravancando o processo educativo, a exemplo do que ocorre no lugar estudado.

O conteúdo desta pesquisa tem sido discutido em vários eventos educacionais nos últimos anos (cito a Anped, 2013, 2015, o Endipe 2014) e tem provocado identificação entre os presentes. As similaridades me levam a crer que o tal "costume" de reunir excluídos em escolas de periferia tem amplitude nacional. O cenário é quase sempre o mesmo, "a escola aonde ninguém quer ir", para onde estão sendo enviados os consumidores falhos, que o "centro não quer".

Recebido em 16/06/2016 e aprovado em 12/08/2016

\section{Notas}

1 Lei da Improbidade Administrativa (Lei 8.429/1992) passou a responsabilizar e a punir gestores por ações que fragilizem a coisa pública.

\section{Referências}

ALMEIDA, Jane Soares de. Mulher e educação: a paixão pelo possível. São Paulo: Edunesp, 1998.

ANDRÉ, Marli Elisa D. Afonso de. Etnografia da prática escolar. 14. ed. São Paulo: Papirus, 1995 (Série Prática Pedagógica). 
Questões sobre os fins e sobre os métodos de pesquisa em Educação. Revista Eletrônica de Educação, São Carlos: UFSCar, v. 1, n. 1, p. 119-131, set. 2007. Disponível em: <http://www.reveduc. ufscar.br>. Acesso em: 9 jul. 2013.

BAUMAN, Zygmunt. Educação e juventude. Rio de Janeiro: Zahar, 2013.

2008.

Vida para o consumo: a transformação das pessoas em mercadoria. Rio de Janeiro: Zahar,

Vida líquida. Rio de Janeiro: Zahar, 2009.

BRASIL. Constituição da República Federativa do Brasil. Brasília, DF: Senado Federal, 1988.

Lei 9.394, de 20 de dezembro de 1996. Estabelece as diretrizes e bases da educação nacional. Diário Oficial [da] República Federativa do Brasil, Brasília, DF: 23 dez. 1996. p. 27.833. Disponível em: <http://www.planalto.gov.br/ccvil_03/LEIS/19394. htm>. Acesso em: 20 ago. 2013.

GEERTZ, Clifford. A interpretação das culturas. Rio de Janeiro: Guanabara Koogan, 1989.

GREEN, Judith L.; DIXON, Carol N.; ZAHARLICK, Amy. A etnografia como uma lógica de investigação. Educação em Revista, Belo Horizonte, v. 42, p. 13-79, dez. 2005. Disponível em: <http:// educa.fcc.org.br/pdf/edur/n42/n42a02.pdf >. Acesso em: 8 maio 2013.

GUBER, Rosana. La etnografia: método, campo y reflexividad. Buenos Aires: Grupo Editorial Norma, 2001. Disponível em: http://pt.scribd.com/doc/6906268/Guber-Rosana-La-Etnografia. Acesso em: 18 jun. 2013.

LEHER, Roberto. Movimentos sociais, democracia e educação. In: FÁVERO, O. \& SEMERARO, G. (orgs). Democracia e Construção do Público no Pensamento Educacional Brasileiro. Petrópolis: Ed. Vozes, 2002.

MEIRELLES, Hely Lopes et al. Direito Administrativo brasileiro. São Paulo: Malheiros, 28ª ed. 2011.

MINAYO, Maria Cecília de S. O desafio da pesquisa social. In: (Org.). Pesquisa social: teoria, método e criatividade. Rio de Janeiro: Vozes, 2012. p. 9-29

SANTOS, Milton. Da totalidade ao lugar. São Paulo: Editora da USP, 2008.

SCHEFER, Maria Cristina. Na periferia das periferias: o não-lugar escolar e a Pedagogia do Destino. 2015 ( 191 f. )Tese (Doutorado em Educação). São Leopoldo: Universidade do Vale do Rio dos Sinos, RS, 2015.

VASCONCELOS, Celso dos Santos. Coordenação do trabalho pedagógico: do Projeto PolíticoPedagógico ao cotidiano da sala de aula. São Paulo: Libertad, 2004.

VEIGA, Ilma Passos A. (Org.). Projeto Político-Pedagógico: uma construção possível. Campinas: Papirus, 2002.

WEBER, Florence. A entrevista, a pesquisa e o íntimo ou por que censurar seu diário de campo? In:

Horizontes Antropológicos. Porto Alegre, n. 32, p. 157-170, jul./dez. 2009. Disponível em: http://www. scielo.br/scielo.php?script=sci_arttext\&pid=S0104-71832009000200007. Acesso em: 04 dez. de 2013. 